THE KURUME MEDICAL JOURNAL Vol. 11, No. 4, 1964

\title{
THE BASIS OF MULTISCINTIGRAM SYSTEM AND ITS CLINICAL APPLICATIONS
}

\author{
OZEKI, M., FURUKAWA, Y., MORIYAMA, T., MATSUSHITA, H. \\ TSUKAMOTO, M. AND KOHI, T. \\ Department of Radiology, Kurume University School of Medicine, \\ Kurume, Japan.
}

(Received for publication December 1, 1964)

\section{BASIS OF MULTISCINTIGRAM SYSTEM}

Recently the radioisotope-scanning is clinically applied not only for the diagnosis of abnormality in thyroid gland, but also for brain tumor and diseases of blood pool, lung, liver, gallbladder, kidney and spleen.

In order to obtain the scintigram for diagnosis, the scanning (in area scanning) had to be done number of times by changing the condition of contraster (eliminative level of the background), rate-down ratio, etc. However, in the actual application for the clinical diagnosis, the scanning takes long time ( 80 minutes for head and 60-90 minutes for liver or kidney). Therefore it is inconvenient to repeat the scanning for several times. To solve this problem, Kuhl ${ }^{1)}$, Friedel $^{2)}$, McIntyre $^{3)}$, Rejali ${ }^{4)}$, Mc Intyre $^{5)}$, Fleming ${ }^{6)}$ and Ephraim ${ }^{7)}$ have applied contrast increasing method, tape-recorder method, and television method. At this point the authors ${ }^{8)-10}$ also contrived a new method 1961, namely Multiscintigram System method differentiated from any previous technique. This method employs a special technique which splits information into several channels according to the count-rate, and records scintigram simultaneously.

By driving the multiple channels in parallel, authors made it possible to record multiple scintigrams simultaneously under various recording factors per each one, with a result similar to that obtained by repeated scannings using an ordinary scintiscanner. This method may be termed as "Multi-Factor scintigram method".

Because the ordinary monochromatic scintigram lacked the quantitative factor, the judgement was only based on the density of patterns empirically.

To modify this matter, the authors drove the multiple channels in series and recorded the splited scintigrms limiting ranges of count-rate which was arranged in sequence. That is to say, each channel responded only the pre-set range and recorded the limited range of count-rate. By this method, quantitative factor was included and it was possible to obtain the better and definite judgement on the scintigram. This method was named as "Multi-Section scintigram method".

Changing the colors of several sections of multisection scintigram which were superimposed, the authors obtained so-called color scintigram. As a whole, authors named this as Multiscintigram System (multiple channel system) and differentiated from the ordinary area scanning, which could be named it as monoscintigram (monochromatic system). Therefore, the author's new method can be classified as follows: 
Multiscintigram System (Multiple Solenoid Scan System)

1. Multifactor Scintigram Method (Multiple Factor Scan Method)

2. Multisection Scintigram Method (Multiple Section Scan Method)

3. Color Scintigram Method (Color Scan Method)

The Apparatus of Multiscintigram System:

Our new model apparatus of Multiscintigram System has 3 more solenoid tapper attached newly to the old apparatus (Shimazu SCC-7)-Crystal NaI 2" $\phi \mathrm{X}^{\prime \prime} 2^{\prime \prime}$, Medical Spectrometer, Honey Comb and Tapered Cone; including the old solenoid tapper, we made it possible to record total of 4 scintigram at the same time (the number can be incrased

Fig. 1 The apparatus of Multiscintigrem System

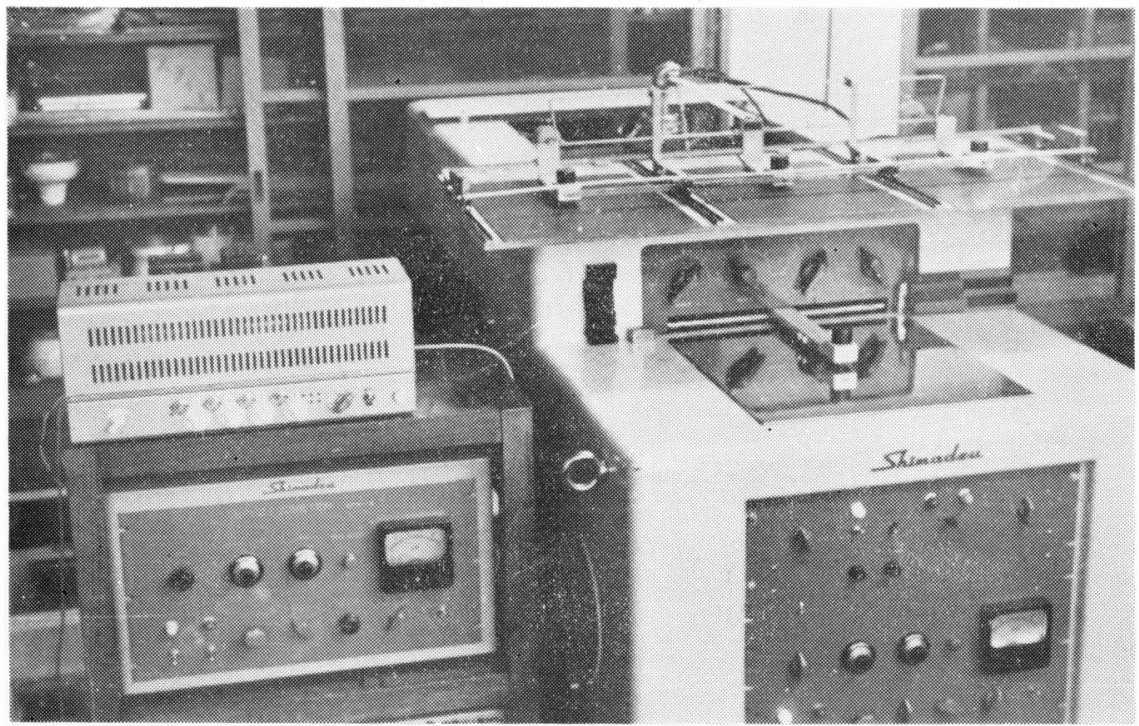

Fig. 2 The blok diagram of the Multiscintigram System, double line is new circuit for the Multiscintigram.

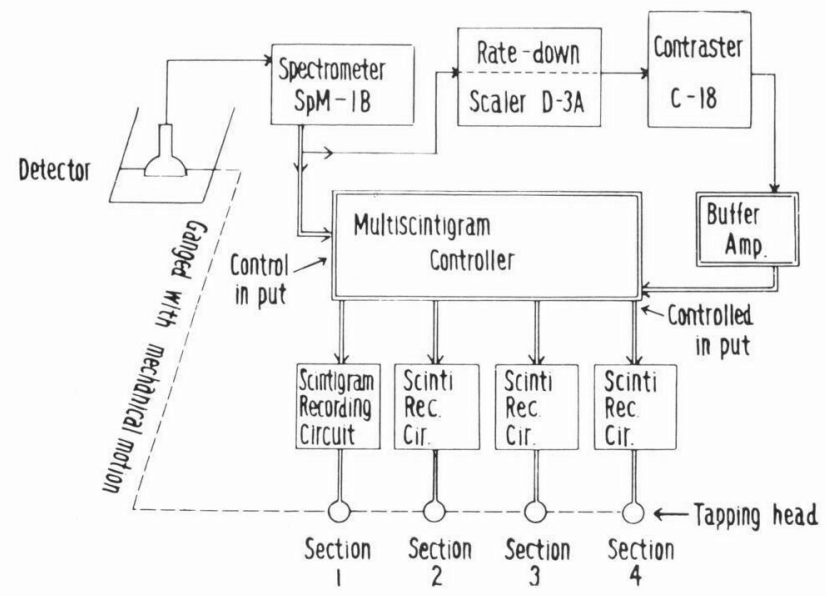


more, but the authors felt four were enough). The actual picture of the apparatus is shown in Fig. 1. Fig. 2 shows its block diagram and the part with double lines shows the new circuit added particulary for the Multiscintigram Syetem. The main element of this method is the Scintigram Controller and it has action of indicate to work any solenoid tapper by the control input.

The informations coming from the detector are analyzed by a spectrometer (i.e., pulse height analyzer) with respect to energy, and extracted as the trigger after the removal of scattering.

The trigger is divided in two ways, one being supplied to the "Control in-put" of the Multiscintigram Controller and the other connected to the "Controlled in-put", via the scaler, rate-down circuit and, if required, a background noise eraser, etc. (Fig. 2). The out-puts from the Multiscintigram Controller are connected to the corresponding recording circuits.

The pulses from the control in-put, after digital analogue conversion, control the matrix which distributes the pulses coming from the controlled in-put to the recording circuits; the matrix acts as a gate for the recording circuits.

The addition of selector makes it possible to use any numbers of the channels of Multiscintigram System as either Multifactor or Multisection Scintigram System.

Model examination of Multiscintigram System:

1. Multifactor Scintigram Method

Fig. 3 (Page 159) shows the Multiscintigram; the $50 \mu \mathrm{c}$. of ${ }^{131} \mathrm{I}$ was made into 50 cc. solution in $100 \mathrm{cc}$. conical flask and the scanning was performed above it. $\mathrm{A}$ is the Multifactor Scintigram (abbreviated as M.F.S.). Varying in size, 4 scintigrams were obtained. In M.F.S. solenoid tappers was driven when the in-put was more than indicated counting rate (threshold level), therefore, scintigrams at 4 different recording factors could be described by only one scanning. This was equivalent to scanning of 4 times in the ordinary monochromatics. This fact means that in M.F.S. the latitude of scintigram is a few times wider than in the monochromatics......this is explained in Fig. 4-A. M.F.S. is to be what is eliminated under the counting rate of each $1,2,3$, and 4 on the sensitivity curve (obtained from the linear scanning of cone flask using rate meter recorder). Factor 1 is the upper remainder of the scintigram which is eliminated under its counting rate 1. Similarly, Factor 2, 3, 4 is the upper remainder of the scintigram which is eliminated under counting rate $2,3,4$, respectively.

2. Multisection Scintigram Method

B in Fig. 3 shows the Multisection Scintigram (abbreviated as M.S.S.) which is obtained from the scanning of same cone flask by multisection method. B in Fig. 4 is the explanation.

In M.S.S. solenoid tapper is driven only in the range of prescribed counting rate for each circuit. Therefore, as in Fig. 3-B, scintigram is recorded as ring shaped pattern except for the circuit driven by the maximum counting rate. Each scintigram here shows the distribution of isocounting rate, so-called isodose curve. By this it is possible to judge the scintigram quantitatively. This is easily understood, by the explanation of $\mathrm{B}$ in Fig. 4. On the vacant portion in the center of section 1 of M.S.S. section 2 is superimposed; in the same manner, 3 is superimposed on section 2 and section 4 on the section 3 .

3. Color Scintigram Method

Color Scintigram (abbreviated as Color S.) can be developed from M. S. S.. It can 
be made by superimposing the sections of M. S.S. in various colors (Fig. 3-C and Fig. 4-C). For this printing, liquid copy graph is most suitable.

The original copy was recorded by the dotting method of M.S.S. using spirit carbon paper (carbon paper of liquid copy graph). The four sections of M.S.S. were dotted using 4 colors (black, green, red and violet) of spirit carbon paper and they were placed on the liquid copy graph in order and printed on a paper superimposing next to next. On the printed section 1 , section 2 was printed, then S. 3 and S. 4 at the last (in the actual use this order could be changed).

M. F. S. and M.S.S. are also printed by this liquid copy graph. Each color in Color S. and each section in M.S.S. shows the isoresponse curve (isodose curve) and quantitative observation of scintigram is then possible; and also, as in M.F.S. it is understandable that latitude in Color S. and M. S.S. is much wider than in Monoscintigram. Therefore, for the quantitative analysis, M. S. S. and Color S. are better than M.F.S. and the authors are using mainly the former 2 for the clinical purposes.

\section{CLINICAL APPLICATION}

\section{Brain Tumor:}

Since Moore ${ }^{11)}$ (1948), in the diagnosis of malignant tumors by RI the most successful case is the brain tumor. Recently other reports have been presented by Bender ${ }^{12)}$, Schumacher ${ }^{13)}$, Blau ${ }^{14)}$, Mcaffee ${ }^{15)}$, Mallard ${ }^{16)}$, Croll ${ }^{17)}$ and others. ${ }^{18)-26)}$ In our department, for the diagnosis of brain tumor, we use RIHSA and ${ }^{203} \mathrm{Hg}$-Neohydrin. For several cases at first we tried ${ }^{131}$ I-DIF, but it showed less positiveness and no longer it is in use. In

TABLE 1

Accuracy of diagnosis by color scintigram for brain tumor histological classified

\begin{tabular}{|c|c|c|c|c|c|c|}
\hline & & H & H & + & \pm & - \\
\hline Glioma & 18 & 4 & 5 & 5 & 2 & 2 \\
\hline astorocytoma & 6 & & 2 & 2 & 1 & 1 \\
\hline glioblastoma & 3 & & 1 & 1 & 1 & \\
\hline oligodendroblastoma & 1 & & & 1 & & \\
\hline oligodendroglioma & 1 & 1 & & & & \\
\hline ependymoma & 1 & & 1 & & & \\
\hline medulloblastoma & 2 & 2 & & & & \\
\hline unclassified glioma & 4 & 1 & 1 & 1 & & 1 \\
\hline Meningioma & 5 & 1 & 1 & 2 & & 1 \\
\hline Craniopharyngioma & 4 & 2 & 1 & 1 & & \\
\hline Acoustic Neuroma & 2 & & & & 2 & \\
\hline Pituitary Adenoma & 4 & & & 2 & 2 & \\
\hline Pinealoma & 2 & & & 1 & 1 & \\
\hline Chordoma & 1 & & & 1 & & \\
\hline Cerebral Sarcoma & 1 & & & 1 & & \\
\hline Metastatic Tumor & 3 & 1 & & 2 & & \\
\hline Histology Undetermined & 11 & & 6 & 3 & 1 & 1 \\
\hline Total & 51 & 8 & 13 & 18 & 8 & 4 \\
\hline Scan Positive & & & 39 & & & 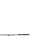 \\
\hline Scan Negative & & & & & & \\
\hline ACCURACY & & & 76 & & & \\
\hline
\end{tabular}


the case of RIHSA and ${ }^{131}$ I-DIF we administered 15 drops of Lugol solution or $5 \mathrm{cc}$ of Jokalon (Iodine Injection) daily as the premedication of 3 to 5 days, while this premedication was not applied in the case of ${ }^{203} \mathrm{Hg}$-Neohydrin.

Since 1962, we performed the Multiscintigram System to 51 cases of brain tumors. The results are showed in Table 1.

\section{Case 1, Ependymoma …........9 years old ……..... femal}

The main complaints were headache, nausea and vomiting. Multisection S. was performed 24, 48, 72 and 120 hours after $360 \mu \mathrm{c}$ of RIHSA was injected intravenously. Figure 5-A (all figures of the "Clinical Application" are shown at the end of this text) shows M. S. S. and Color S. after 120 hours showing Section 2, 3, 4, and Color S. from the left. Fig. 5-B shows a comparison of patterns among the time of scannigs. For easy comparison, these were abstracted only the highest section (S. 4) of each scannings and showed the lesion of the brain tumor. This lesion was in accordance with that of encephaloangiography (Fig. 6). An operation was performed for this case. The lesion was motor area of the latter lobus frontalis cerebri and it was in accordance with the diagnosis made by M.S.S. and Color S.. Histological diagnosis was ependymoma.

Case 2, Meningioma...........40 years old...........male

The main complaints were diplopia, dysmnesia and headache. For this patient both RIHSA and ${ }^{203} \mathrm{Hg}$-Neohydrin were used. Scanning by ${ }^{203} \mathrm{Hg}$-Neohydrin (intraveneous injection of $480 \mu \mathrm{c}$ ) was performed at the beginning time and, 10 days later, that by RIHSA (i. v. injection of $450 \mu \mathrm{c}$ ) was done. Fig. 7 and 8 show the color S. of ${ }^{203} \mathrm{Hg}$ Neohydrin and RIHSA, respectively. In comparison of those two color S., we know that RIHSA was better than ${ }^{203} \mathrm{Hg}$-Neohydrin in the uptake to brain tumor. An operation was performed and the localization of the lesion was in accordance with the diagnosis made by Color S.. The histological diagnosis was meningioma.

Case 3, Astrccytoma…........17 years old …….... female

The main complaints were headache and nausea. Fig. 9 shows the Color S. of this female. The dots of scintigram are mostly green (section 2), but they are localized sharply and show very clearly the lesion of the tumor. This was in accordance with the findings of encephaloangiography (Fig. 10).

It should be noted in this case that the lesion was pointed out more clearly by the scintigram. Operation was performed and it was confirmed that this was astrocytoma.

II Thyroid Gland:

Thyroid gland is one of the organs for which the diagnosis by RI is mostly applied. Tow cases among many scintigram performed in our department are illustrated here.

Case 1, Normal Thyroid Gland …........30 years old............female

Multiscintigram of normal thyroid gland is shown. (Fig. 11) From the left, Section 2, 3, 4 and Color S. are observed: isodose curve is drawn, but this relationship is better illustrated in Multisection.

Case 2, Carcinoma of Thyroid Gland ............38 years old ............female

Fig. 12 shows the Color Scintigram of this patient. The defect at the right below of the Color Scintigram shows the lesion of the tumor.

III Liver:

Liver Scintigram was performed first by Stirret and Yuhl ${ }^{27)}$ et al. in 1953 using ${ }^{198} \mathrm{Au}$ colloid and since then many scholars have tried it using various radioisotope and labelled 
compounds.

Recent studies have been reported by Power ${ }^{28)}, \mathrm{Krober}^{29)}, \mathrm{Bonte}^{30)}, \mathrm{Yagen}^{31)}, \mathrm{Crespo}^{32)}$, Feldman ${ }^{33}$ and others ${ }^{34)-38}$ ) in which ${ }^{198} \mathrm{Au}$ colloid was mostly used because of the superiority in its selective uptake and depositing time.

We also administered $400 \mu \mathrm{c}$ of ${ }^{198} \mathrm{Au}$ collid by injection and performed Multiscintigram 3 hours thereafter.

Case 1, Metastatic Liver Cancer...........72 years old …........male

Suspecting the liver metastasis of laryngeal cancer, liver scintigram was performed. Fig. 13 shows the Multiscintigram (Section 2, 3, 4 and Color S. from bottom). In M. S.S. section 1 (black) was omitted. In the adjacent part to the right lobe of the center of the liver, no violet dots (S. 4) were observed, but red (S. 3) and Green (S. 3) dots were present. This was more clear when M.S.S. was comparatively observed; this lesion was the location of the tumor. We made a diagnosis as the metastatic liver cancer and it was proved by biopsy as the metastasis of laryngeal cancer.

Case 2, Liver Cancer...........52 years old...........male

Only the Color S. is shown in Fig. 14 for this case. In Color S. not only the violet dots (S. 4), but also red dots (S. 3) were scarce and they were mostly green (S. 2). This meant the poor uptake of ${ }^{198} \mathrm{Au}$ colloid to liver and high degree of disturbance in the liver function.

As a whole in viewing the shape, the defect was observed at the lower edge of the liver, meaning that this was in accordance with cancer and infiltration was spread all over the liver. Spleen was clearly described, but this was due to the disturbance in liver function. Biopsy proved that the patient had liver cancer.

IV Kidney:

The history of kidney scanning is rather new and the first trial was done by Schumacher ${ }^{13)}$ in 1960 using ${ }^{131}$ I-Urographin. In the same year Mcaffee $^{39)}$ also tried it using ${ }^{203} \mathrm{Hg}$-Neohydrin. Thereafter, Morgan ${ }^{40)}$ and Westphal ${ }^{41)}$ (1961) and Izenstark ${ }^{42)}$ (1962) tried kidney scanning using ${ }^{131} \mathrm{I}$-diodrast and ${ }^{131} \mathrm{I}$-hippuran, respectively. However those compounds labelled with ${ }^{131} \mathrm{I}$ are quick in excretion, since they were originally to be used for renogram and they were not proper for kidney scintigram which require about 60-90 minutes. Above mentioned scholars tried the kidney scanning by dividing the compounds,by instillation or by stop flow using urettal catheterization.

The most suitable scanning for Kidney is ${ }^{203} \mathrm{Hg}$. Neohydrin which has 3 hours of biological HL (McAfee $\left.{ }^{39}\right)$ ). Therefore, we used this compound to perform multiscintigram.

Case 1, Essential Renal Bleeding ……....55 years old $\cdots \cdots \cdots \cdots \cdots$....male

The main complaint was renal bleeding. Pyelogram (Fig. 15) did not show much abnormality. . By the uretral catheterization it was diagnosed as essential bleeding of the left kidney. Figure 16 shows the M.S.S. showing the section 2, 3, 4 and Color S. from the bottom. Similarly the scintigram was almost normal, but the left kidney (the left in the figure) had less violet dots (Section 4) than the right kidney and this meant the slight disturbance of the kidney function, and this was in accordance with the finding of ureter catheterization. In the M.S.S. and Color S. of normal kidney, the equivalent sensitive ring clearly appeared like this.

Case 2, Renal Papillary Carcinoma ….......51 years old $\cdots \cdots \cdots \cdots \cdots$ female

The main complaint was renal bleeding. The ureter catheterization showed the bleeding from the right kidney. There was no specific finding in pyelogram (Fig. 17) 
and other examinations. Urologically, it was almost diagnosed as essential renal bleeding of unknown cause. However, kidney scanning showed less violet dots (S. 4) on both sides of Color S. as shown in Fig. 18 and red dots (S. 3) were also scarce. Besides, it didn't show clear equivalent sensitive ring which was observed in Case 1. This was more clear in the right kidney (right of the picture) and the shape of the kidney could not be observed clearly. It showed the disturbance of function in both kidneys, especially in the right. The operation of the right kidney proved that it was papillary carcinoma. In this case, Scintigram, especially Multiscintigram was a great help to diagnose the organic change which might have be handled as simple renal bleeding otherwise.

Case 3, Renal tuberculosis...........30 years old............ female

The main complaint was renal bleeding. This patient was diagnosed tuberculosis of both kidneies by clinical examination. There was no shadow of both kidneys in pyelogram as shown in Fig. 19, so it could not be decided by pyelogram which side of kidney should be extirpated. However, kidney scanning showed some remain of function in the left kidney as shown in Fig. 20. Therefore, this patient was extirpated the right kidney.

V Lung :

The history of lung scanning is very new. This was performed first by Taplin ${ }^{43) 44)}$ (1963) and continuously by Wagner ${ }^{45)}$, Quinn ${ }^{46)-18)}$ and others ${ }^{49 / 50)}$.

They used suspension of ${ }^{131}$ I-macroaggregated albumin (MAA) and tried mainly inspection of regional pulmonary blood flow. We show several pulmonary scintigrams using ${ }^{131}$ I-MAA by our Multiscintigram System.

Case 1, Pleuritis hypertrophycans...........57 yeas old …........male

$\mathrm{X}$-ray film of this patient show Fig. 21. The tumor like shadow of lower lobe of left lung is pleura adhesion. Fig. 22 is the color scintigram of this patient. The defect at the left below shows the lesion of pleuritis hypertrophycans.

Case 2, Lung cancer...........55 years old............female

The disease history of this case was lung cancer of upper hilium at the right lung as shown in Fig. 23. This tumor was applied ${ }^{60} \mathrm{Co}$-teletherapy $(8,000 \mathrm{r})$ and now has been disappered as shown in Fig. 24. On the color scintigram (Fig. 25), no dots were observed or only green dots were present at this recovered lesion of the lung. This poor concentration of radioactivity means that the fibrosis of lung has been produced by ${ }^{60} \mathrm{Co}$-irradiation and there is a diminished blood flow of that region.

\section{DISCUSSION}

The authors contrived the new Multiscintigram System which was experimented in the model and clinically applied for the diagnosis of brain tumor and diseases of lung, liver, kidney and thyroid gland. The characteristics of this system could be summarized as follows;

1. In Multiscintigram, namely both the Multifactor S. and Multisection S., it was possible to obtain the most valuable scintigram for the clinical diagnosis only by one scanning; latitude was much wider than the monochromatic method (monoscintigram).

2. In Multisection S. besides the enlargement of latitude, the scintigram could be judged quantitatively and the diagnosis is more accurate. 
3. Each section in Multisection S. shows the equivalent isodose curve; using various colors, superimpose of each section provide simply the color scintigram.

4. The comparative judgement for both in Color S. and Multisection S. made the diagnosis more accurate.

5. In the actual application, Multisection S. was more convinient than Multifactor S. for the present.

Color scintigram was recently done by Mallard ${ }^{16 / 51)}$ in England (1959-1961); he used dotting method of scintigram using multicolors tape and thereafter several trials are done by Kakehi ${ }^{52)}$ and others ${ }^{53)}$. Their method were entirely different from ours. The characteristics of our color scintigram could be summarized as follows:

1. In the midst of scanning the recording circumstance of the scintigram could be observed and examined at any time.

2. The observation of not only the color scintigram, but also the Multisection S. (which is the prestep of Color S.) made the judgement easier and more accurate.

3. Any necessary number of copies could be printed in a short time.

4. It is very economical.

5. In the case of using scintigram, this could be used as a routine.

For the clinical application authors mainly used Multisection S. and Color S. The authors experienced the fact that the diagnosis could be accurately made by one scanning by our system and the applicable value was much higher in comparison with the ordinary Mono-Scintigram. For the diagnosis of liver or kidney diseases this method was not so proper and accurate as functional test like radioisotope hepatography or radioisotope renography, but at least it could tell the damage in the function to some extent.

\section{SUMMARY}

The authors contrived the Multiscintigram System as the new method of scintiscanner. This was consisted of Multifactor Scintigram, Multisection Scintigram and Color Scintigram. However, Multisection Scintigram is the prestep of Color Scintigram and these two can not be separated.

The characteristics of this system was that it was possible to obtain the most valuable scintigram for the clinical diagnosis by only one scanning (the latitude of scintigram was very wide). Further, more quantitative analysis was possible for both Multisection Scintigram and Color Scintigram.

The authors applied this method Clinically for the diagnosis of brain tumor, diseases of lung, liver, kidney and thyroid gland, and proved that its applicable value was much higher in comparison with the monochromatics and the diagnosis was more accurate. The authors clarified also that this method could be used to some extent for the function test of liver and kidney.

\section{REFERENCES}

1. Kuhl, D. E., Chamberlain, R. H., Hale, J. And Gorson, R. O.: "A high contrast photographic recorder for scintillation counter scanning." Radiology, 66, 730 (1956)

2. Friedel, H. L., Mcintyre, W. J. and Rejali, A. M.: "A method for the visualization of the configurations and structure of the liver. Part A. Preliminary clinical investigation". Am. J. Roentgenol., 77, 455 (1957) 
3. MCINTYRe, W. J. AND Houser, T. S.: "Method for visualizing configuration and structure of the liver. Part B. Counting rate cut-off circuit for increased contrast in automatic scanning"'. Am. J. Roentgenol., 77, 471 (1957)

4. Rejali, A. M., Mcintyre, W. J. And Friedel, H. L.: "A radioisotope method of visualization of blood pools." Am. J. Roentgenol., 79, 129 (1958)

5. Mcintyre, W. J., Friedel, H. L. And Crespo, G. G.: "The visualization of internal organs by accentuation scintillation technics”. Radiology, 73, 329 (1959)

6. Fleming, W. H., McIraith, J. D. And King, E. R.: "Medical scintillation scanning utilizing closed circuit TV contrast enhancement.: Technical aspects”. Am. J. Roentgenol., 87, 128 (1962)

7. Ephraim, K. H.: "Detection of liver tumors with colloidal radiogold. A new method of high contrast photoscanning." Am. J. Roentgenol., 87, 141 (1962)

8. OzEKI, M.: "Diagnostic application of radioisotope; Especially radioisotope scanning of malignant tumor, (the report of Multiscintigram, No. I)', (in Japanese), Nipp. Acta. Radiol., 22, 448 (1962)

9. OzEKI, M.: Clinical application of Multiscintigram method (color scintigram)'”. (In Japanese), Proceedings of the 5th Conference on Radioisotopes, 1-93 (1963)

10. Ozeki, M., Furukawa, Y. ET AL.: "Study of the Multiscintigram method". (in Japanese), Proceedings of the 5th Conference on Radioisotopes, 3-148 (1963)

11. Moore, G. E.: "The use of radioactive diiodofluorescein in the diagnosis and localization of brain tumors”. Science, 107, 569 (1948)

12. Bender, M. A.: (in discussion on papers by Sweet and Planiol), Medical Radioisotope Scanning, I. A. E. A., Vienna, 203 (1959)

13. Schumacher, W. ET AL.: "Die Darstellung von Hirn-Nierentumoren durch die positiven oder negativen Kontraste im nicht linearen Photogammagram”. Strahlentherapie, 113, 432 (1960)

14. Blau, M. AND Bender, M. A.: "Cliinical evaluation of $\mathrm{Hg}^{203-N e o h y d r i n ~ a n d ~ I 131-a l b u m i n ~ i n ~}$ brain tumor localization”. J. Nuclear Med. 1, 106 (1960)

15. McAfee, J. G. AND TAXDAL, D. R.: "Comparison of radioisotope scanning with cerebral angiography and air studies in brain tumor localization”. Radiology, 77, 207 (1961)

16. Mallard, J. R., Fowler, J. F. ANd Sutton, M.: "Brain tumor detection using radioactive arsenic." Brit. J. Radiol., 34, 562 (1961)

17. Croll, M. N. ET AL.: "Brain tumor localization utilizing mercury 203". Radiology, 76, 635 (1962)

18. Jacobson, L. E., Miller, W. N., Hillsinger, W. R. and Einstein, F. S.: "The use of 'tumor' and 'brain' phantoms in the interpretation of positron annihilation and unbalance scans of brain tumor”. Am. J. Roentgenol., 88, 339 (1962)

19. AshkenAZY, H. M. ET AL.: "The localization of intracranial space-occupying lesions by fuloborate ions labelled with fluorine 18”. Am. J. Roentgenol., 88, 350 (1962)

20. Wende, S.: “Ergebnisse der Hirntumor Diagnostic mit radioaktiven Substanzen”. Acta Radiologica, 1, 972 (1963)

21. Di Chiro, G. ET AL.: "RIAF-radio-iodinated anti-fibrinogen encephalography-Preliminary experiences”. Acta Radiologica, 1, 967 (1963)

22. KRAmer, S. ET AL.: "The value of $\mathrm{Hg}^{203}$ brain scana in patients with intracranial hematomas". Radiology, 83, 902 (1964)

23. Gottschalk, G. AND ANGER, H. O.: "The sensitivity of the positron camera for detecting simulated brain tumors with Gallium 68-EDTA”. Am. J. Roentgenol., 92, 174 (1964)

24. FEINDEL, W. ET AL.: "Contour brain scanning with iodine and mercury compounds for detection of intracranial tumors”. Am. J. Roentgenol., 92, 177 (1964)

25. Ozeki, M., Furukawa, Y. And Noguchi, S.: "Diagnosis of brain tumor with radioisotope. (the report VI)”. Jap. Nuclear Med., 3, 16 (1963),

26. OzEKI, M.: "The value of radioisotopic diagnosis for brain tumor and case report”. (in Japanese), Nipp. Clinical Radiology, 9, 937 (1964)

27. StiRret, L. A. AND YUhL, E. T.: “Hepatic radioactive survey”. Radiology, 61, 930 (1953)

28. Powers, J. C. ET AL.: "Scintigraphy and porteinosis.-Their value in the diagnosis of liver disease”. Radiology, 74, 912 (1960) 
29. Krohmer, J. S. AND Bonte, F. J.: "Scintillation scanning of the liver.: I. Physical basis". Am. J. Roentgenol., 88, 269 (1962)

30. Bonte, F. J., Krohmer, J. S. ET AL.: "Scintillation scanning of the liver.: II. Clinical applications”. Am. J. Roentgenol., 88, 275 (1962)

31. Yagan, R., MCINTyRe, W. J. Et AL.: "Estimation of liver size by the multiple cut-off scintillation scanning technique”. Am. J. Roentgenol., 88, 289 (1962)

32. Crespo, G. G. AND McIntyre, W. J.: "A comparison of I131 Rose Bengal and colloidal Au198 in liver scanning”. Am. J. Roentgenol., 87, 161 (1962)

33. Feldman, F., Rubenfeld, S. And Collica, C.: "The radioactive (131I) rose bengal hepatoscan." Radiology, 79, 457 (1962)

34. GERShON-COHEN, J. ET AL.: "Contrast roentgenography versus radioisotope scanning of liver and spleen”. Am. J. Roentgenol., 88, 304 (1962)

35. Sinner, W.: "Das szintigraphische Bild der Leber nach intravenöser Gabe von radioaktiven Kolloidalem Gold (Au198)”. Fort. Schr. Roentg., 97, 286 (1962)

36. Cristie. J. H., McIntyre, W. J. ET AL.: "Radioisotope scanning in hepatic cirrhosis". Radiology, 81, 455 (1963).

37. CzerniAK, P. ET AL.: "Radioisotopic scanning in liver echinococcosis". Radiology, 83, 690 (1964)

38. KUHL, D. E. ET AL.: "Cylindrical and section radioisotope scanning liver and brain". Radiology, 83, 926 (1964)

39. MCAfEe, J. G. AND WAgner, H. N.: "Visualization of renal parenchyma by scintiscanning with Hg203 Neohydrin”. Radiology, 75, 820 (1960)

40. Morgan, M. C. ET AL.: "Scintiscanning dog kidneys using diodrast I131". Am. J. Roentgenol., 85,125 (1961)

41. Weastphal, R. D. et AL.: "Delineation of human kidney by scintillation scanning". Am. J. Roentgenol., 87, 161 (1962)

42. IzenstaRK, J. L. ET AL.: "Renal scanning using stop flow”. Radiology, 78, 425 (1962)

43. TAPLIN, G. V. ET AL.: "Colloidal radioalbumin aggregates for organ scanning”. Scientific Exhibit 10th Annual Meeting of Society of Nuclear Medicine, June 26-29, 1963. Montreal

44. TAPLIN, G. V. ET AL.: "Suspension of radioalbumin aggregates for photoscanning the liver, spleen, lung and other organs”. J. Nucl. Med. 5, 259 (1964)

45. Wagner, H. N., Sabiston, D. C., Iio, M., McAfee, J. G., Meyer, J. K. And Langan, J. K• : "Regional pulmonary blood flow in man by radio isotope scanning". J. A. M. A., 187, 601 (1964)

46. Quinn, J. L. III., Whithley, J. E., Hudspeth, A. S. AND Prichard, R. W.: "Early clinical applications of lung scintiscanning". Radiology, 82, 315 (1964)

47. Quinn, J. L. III., Whithley, J. E., Hudspeth, A. S. And Watts, F. C. : "An approach to the scanning of pulmonary infracts”. J. Nuclear Med., 5, 1 (1964)

48. Quinn, J. L. III. AND Whithley, J. E. : “Lung scintiscanning”. Radiology, 83, 937 (1964)

49. Whithley, J. E., Quinn, J. L. III., Hudspeth, A. S. ANd Prichard, R. W.: "The scintiscanning of experimentally produced pulmonary infracts”. Radiology, 81, 884 (1963)

50. Lopez-MAJANO, V. ET AL.: "Comparison of radioisotope scanning and differential oxygen up take of the lungs". Radiology, 83, 697 (1964)

51. Mallard, J. R. AND Peachey, C. J.: "A quantitative automatic body scanner for the localisation of radioisotopes in vivo". Brit. J. Radiol., 32, 652 (1959)

52. Kakehi, H., ARimizU, N. ET AL, : "A new method for color scanning". Symposium on Medical Radioisotope Scanning, I. A. E. A., Athens, 20-24, April, 1964.

53. NishibORI, K., KURIBAyASHI, S. AND KATO, T.: “RI color scanning apparatus”. (in Japanese), Proceedings of the 5th Conference on Radioisotopes 3-15 (1963) 


\section{ILLUSTRATIONS}

\section{Model Examination}

On the Multiscintigram System simultaneous recording of four channels was used and the recordings were performed by different colors. The colors are black, (section-1), green(sec.-2), red (sec. - 3) and violet (sec.-4) and these sections response in sequence from lower to higher of the activity.

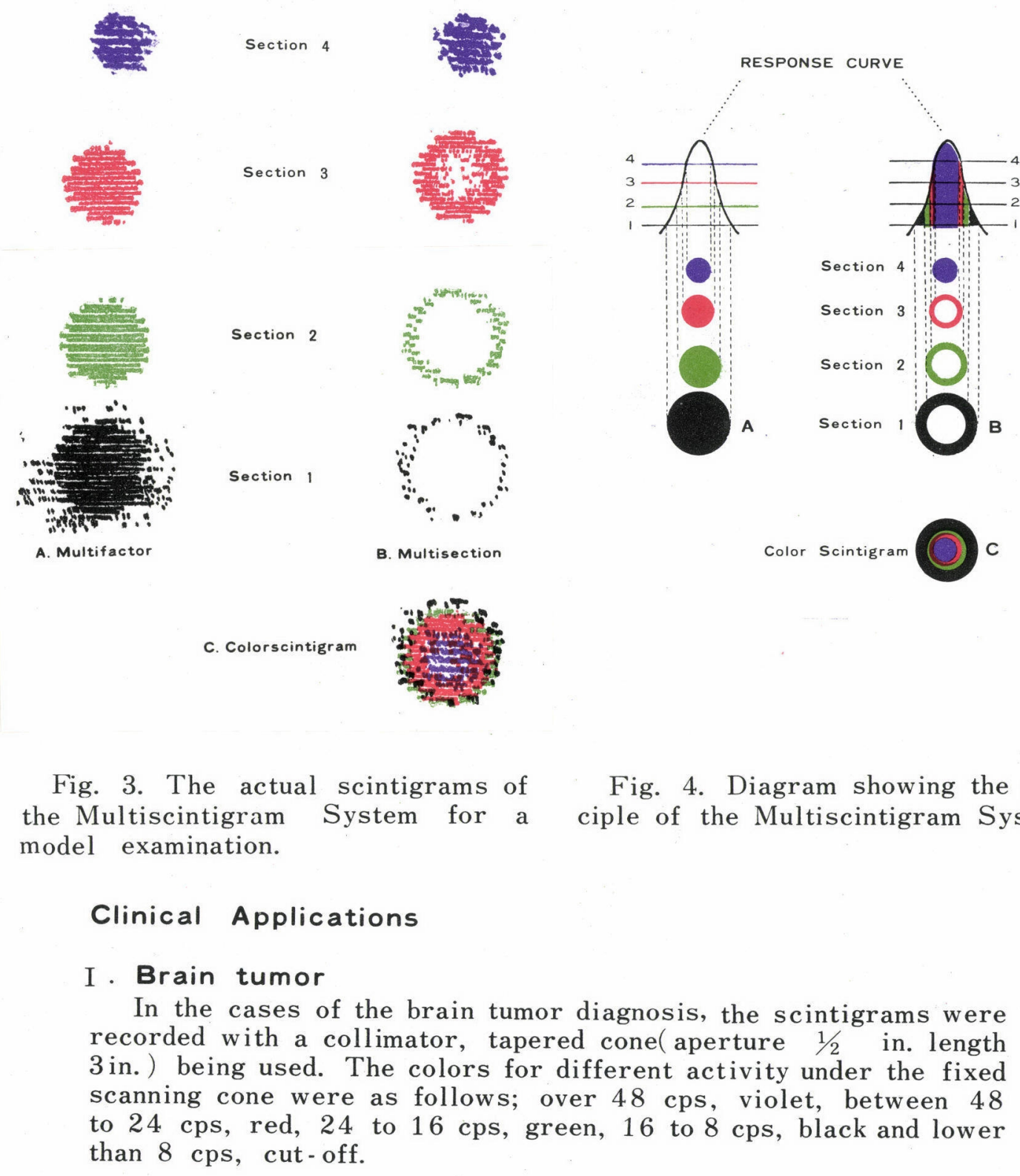




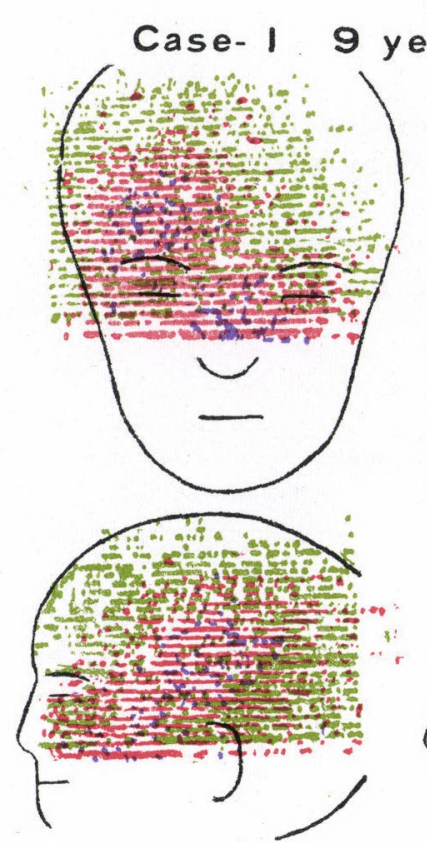

Color $\mathrm{S}$.
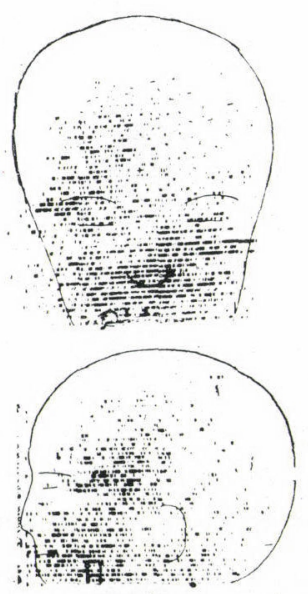

$24 \mathrm{hr}$.

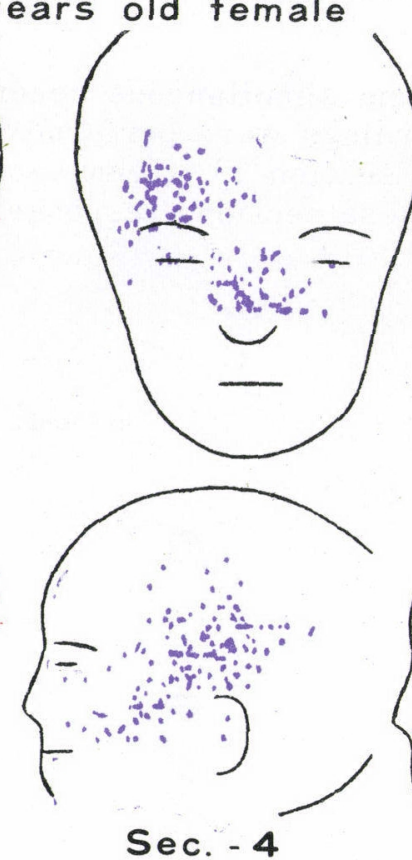

Fig. 5 .
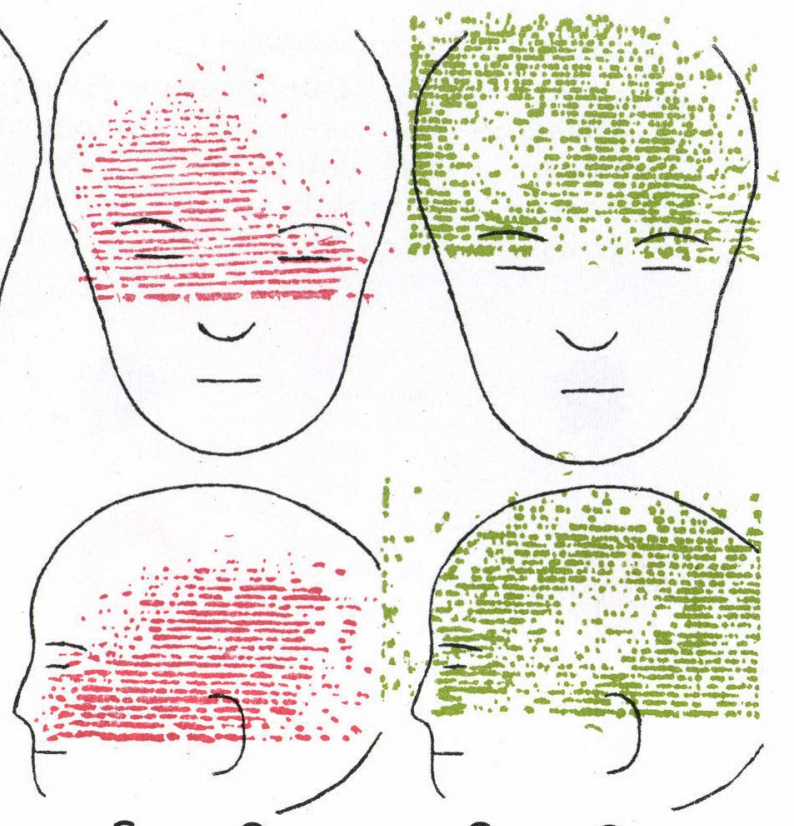

Sec. -2

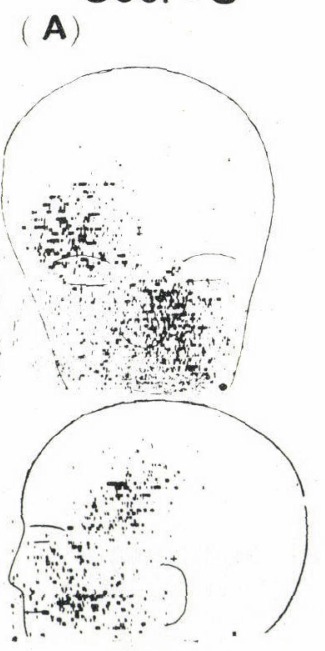

$72 \mathrm{hr}$.

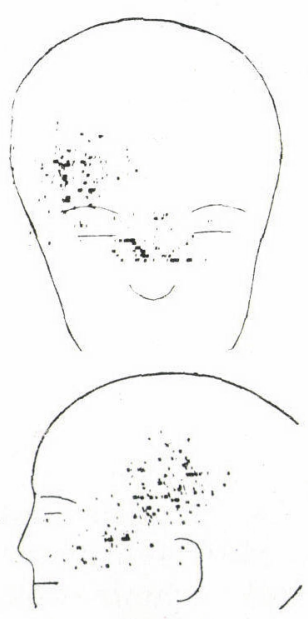

$120 \mathrm{hr}$.

Fig. 5. (B)

Fig. 5.RIHSA scan of a patient who was proved to have a ependymoma by surgical operation. The abnormal area showing an increased uptake well corresponded with the lesion and the activity remained for comparatively longer time in this area compared with other healthy area. Scannings were performed 24, 48, 72, and 120 hours after injection $(360 \mu \mathrm{c}$.).

(A): Section scintigrams and color scintigram at 120 hours, by the Multiscintigram System.

(B): a comparison of patterns among the times of scanning. 

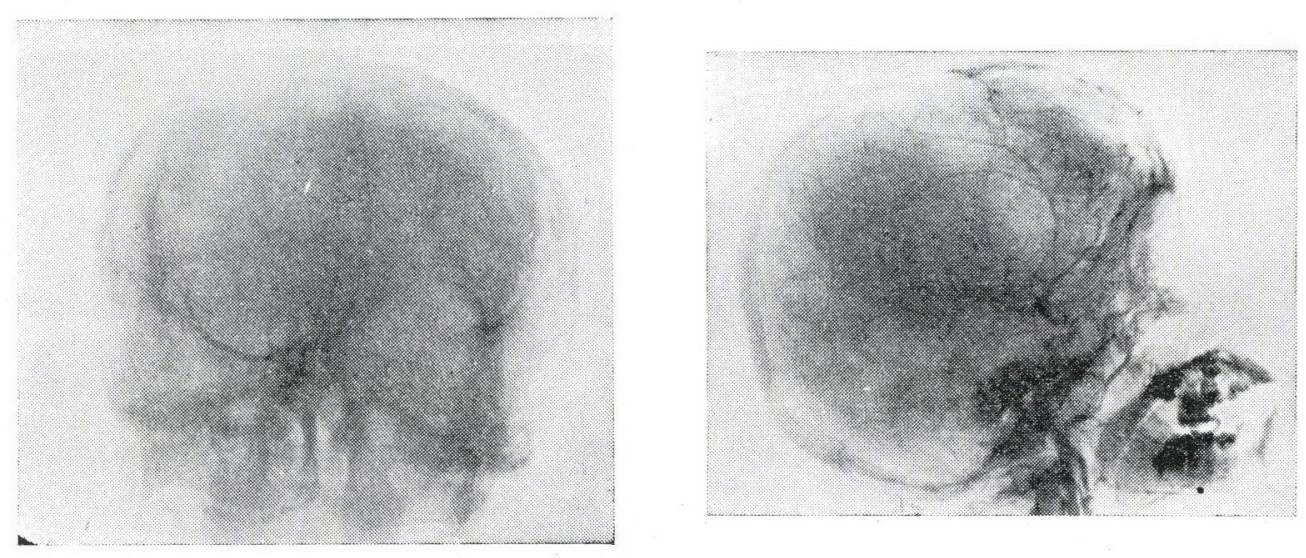

Fig.6. Encephaloangiography of ependymoma.

\section{Case- 2}

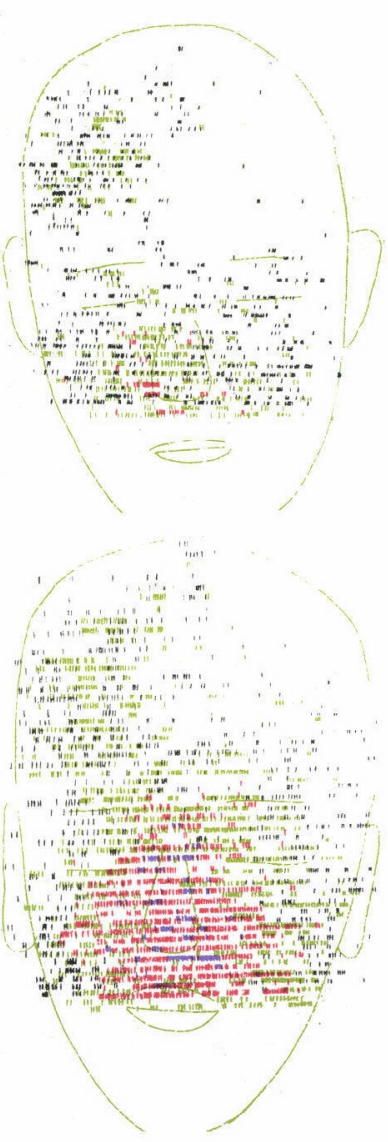

40 years old male

Fig . 7. $203 \mathrm{Hg}$ Neohydrin scan of a patient who was proved to have a meningioma by surgical operation. Scanning was performed 3 hours after I. $\mathrm{V}$. injection $(480 \mu \mathrm{c})$.

Fig. 8. RIHSA scan of the patient same as above. Scannings were performed 24 and 48 hours after injection $(450 \mu \mathrm{c})$ and the scintigram was at 48 hours. In this case, the patient was received both RIHSA and Neohydrin, scan, comparatively, RIHSA showed a better localization of tumor pattern. 


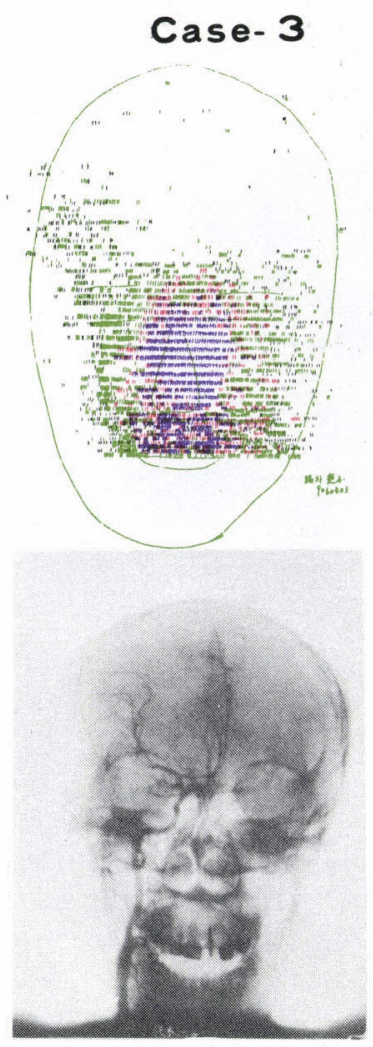

\section{7 years old female}

Fig. 9. RIHSA scan of a patient who was proved to have.a astrocytoma by sur. gical operation. Scanning was performed 24 and 48 hours after injection $(420 \mu \mathrm{c})$.

Pattern of tumor was clear

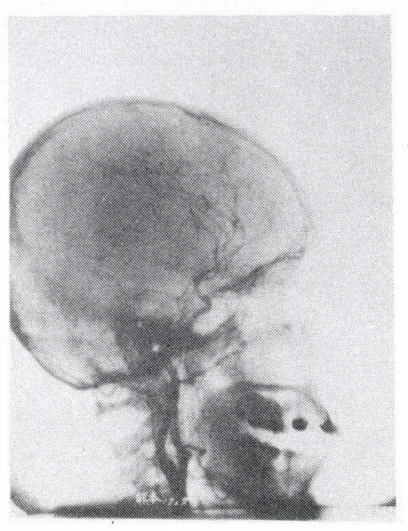
and it was corresponded with the result of operation.

Fig. 10. Encephaloangiography of astrocytoma.

\section{II . Thyroid Gland}

The scans of thyroid gland was performed 24 hours after oral administeration of iodine $(100 \mu \mathrm{c})$. For the scanning a honey-comb collimator, 19 holes, focus $5 \mathrm{~cm}$., was used. The colors for different activity was set as same as following the cases of liver scans.

\section{Case- I 30 years old female}

Case- 2
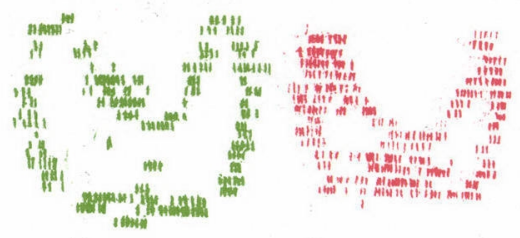

Sec. -3

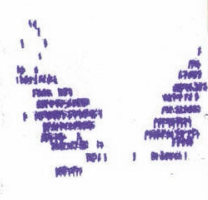

Sec. -4

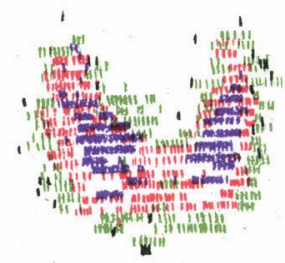

Color s.

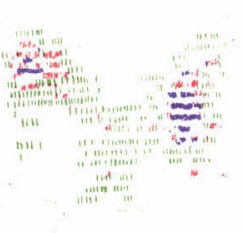

Fig. 12.

Fig. 11. Multiscintigram of normally thyroid gland.

Fig. 12 . Color scintigram of thyroid cancer ( 38 years old female). 


\section{III . Liver}

In the cases of liver scannings, a honey-comb collimator, focus $10 \mathrm{~cm} .39$ holes, was used. Scanning was performed one hour after I.V.injection of $198 \mathrm{Au}$ colloid. Dose rate was $7 \mu \mathrm{c} / \mathrm{kg}$.

The colors for different activity under the fixed scanning cone were as follows; over $64 \mathrm{cps}$, violet, between 64 to $36 \mathrm{cps}$, red, 36 to $18 \mathrm{cps}$, green, 18 to $8 \mathrm{cps}$, black and lower than $8 \mathrm{cps}$, cut - off.

\section{Case- I 72 years old male}

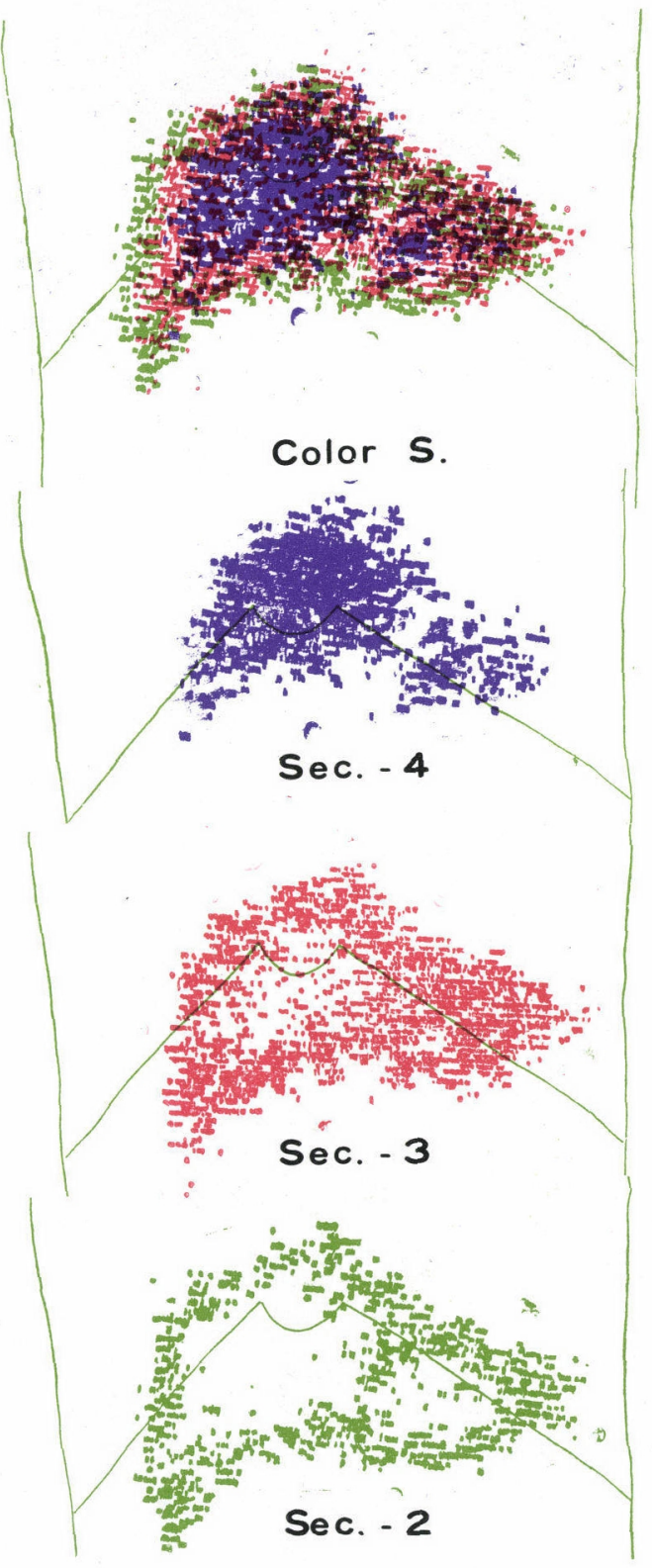

Fig. 13. Multiscintigram of metastastic liver cancer $198 \mathrm{Au}$ colloid $(420 \mu \mathrm{c})$. A section scintigram means the equivalent iso-dose distribution. By the observation of both section and color scintigram, we understand the complicated isotopic distribution in the organ.

\section{Case- $2 \quad 52$ years old male}

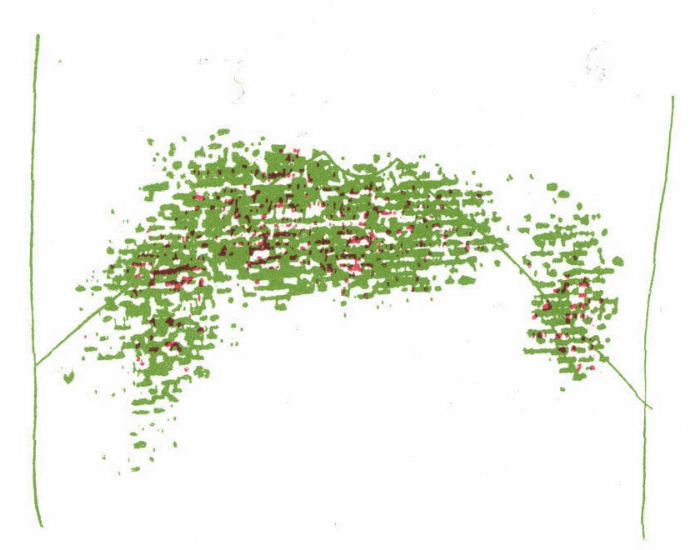

Fig. 14. Color scintigram of livrer cancer, $198 \mathrm{Au}$ colloid $(420 \mu \mathrm{c})$. This patient was proved to have a liver cancer by biopsy. The liver pattern was deformed and accompanied with splenic pattern, so we can recognize the disturbance in liver function. 


\section{IV . Kidney}

In the cases of kidney scans, about $60 \mu \mathrm{c}$ of $203 \mathrm{Hg}$-Neohydrin was used. The scanning was started about at one-half hours after injection. For the scanning, a tapered cone, $1 / 2$ in. aperture, was used. The colors for different activity were as follows; over $48 \mathrm{cps}$, violet, between 48 to $24 \mathrm{cps}$, red, 24 to 16 , green, 16 to $8 \mathrm{cps}$, black and lower than $8 \mathrm{cps}$, cut-off.

Case- I

55 years old male

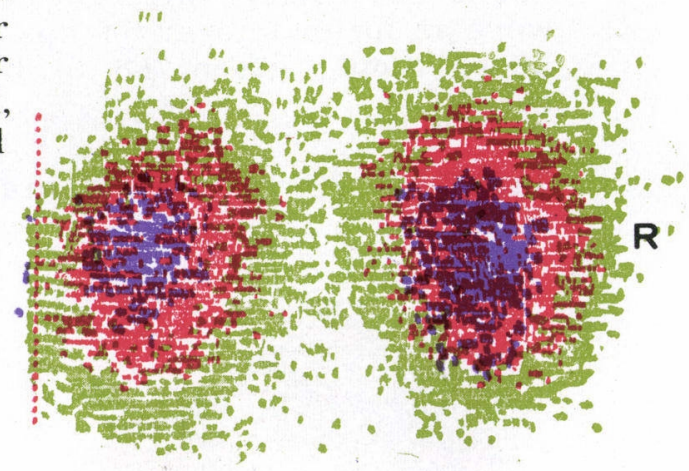

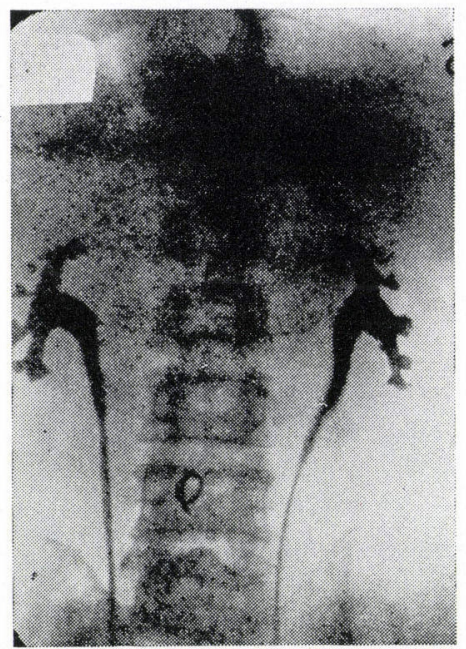

\section{Color S.}
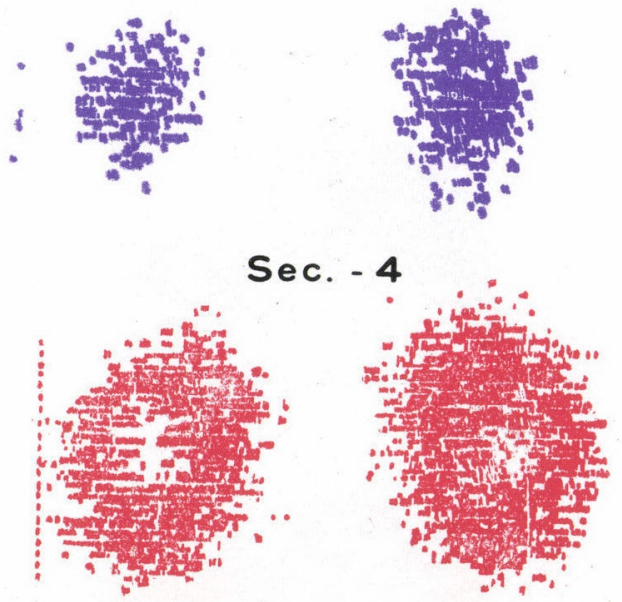

Fig. 15. Pyelogram of essential renal bleeding.

Fig. 16. Multiscintigram of essential renal bleeding. Section scintigrams showed a complicated isotopic distribution in the organ, and also aided to obtain an accurate diagnosis.
Sec. -3

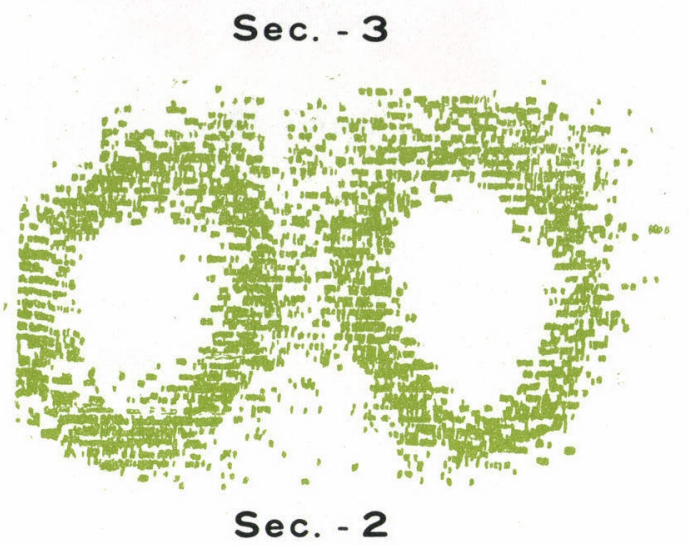




\section{Case- 251 years old female}

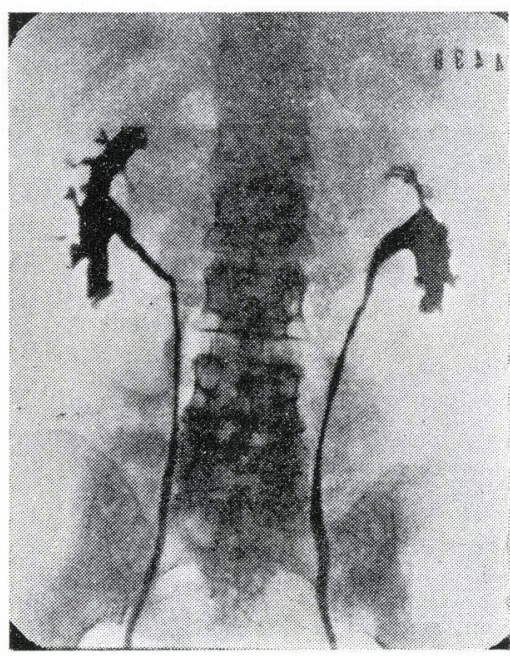

Fig. 17. Pyelogram of renal papillary carcinoma.

Case- 330 years old female.

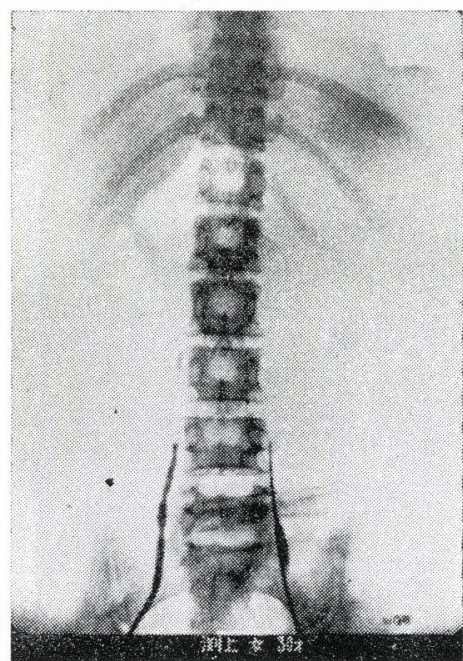

Fig. 19. Pyelogram of renal tuberculosis.

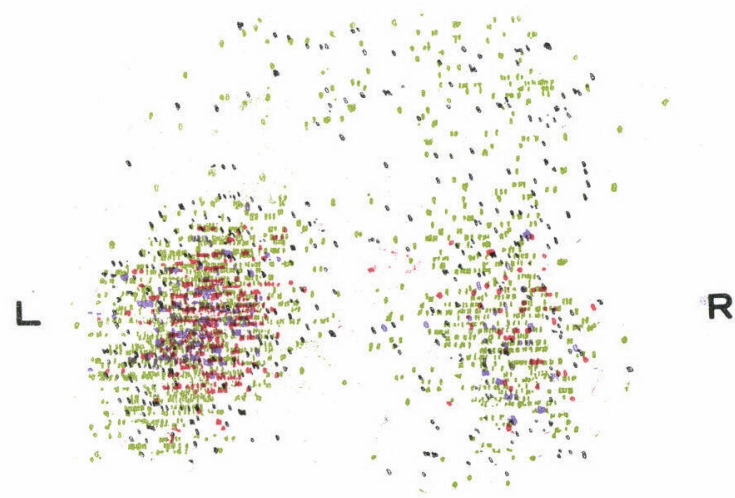

Fig. 18. Color scintigram of renal papillary carcinoma (right). This patient had a renal bleeding.

The activity in both side of the finding of color scintigram was weak; this showed a heavy disturbance of function, particularly in the right side.

The diagnosis was proved by surgical operation.

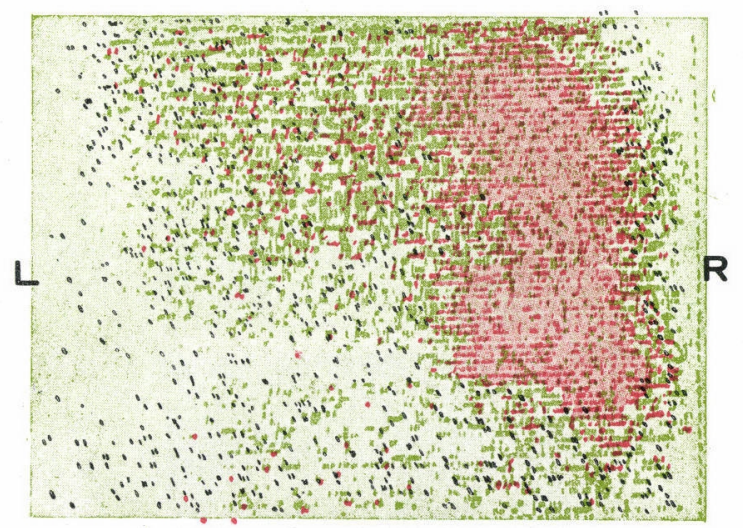

Fig. 20 . Color scintigram of renal tuberculosis (left).

As scintigram showed the function of kidney, we could pointed out some remained activity in the left side, but nothing in the right side. Therefore, the right kidney was extirpated. 


\section{Lung}

In the cases of lung, MAA were used. Usually we applied a tapered cone, $1 / 2$ in. aperture, and about $120 \mu \mathrm{c}$ of MAA to a patient. But when a honey-comb collimator was used, doses were required 350 to $400 \mu \mathrm{c}$. A scanning was started immediately after injection.

The colors for different activity were as follows; over $64 \mathrm{cps}$, violet, between 64 to $36 \mathrm{cps}$, red, 36 to $18 \mathrm{cps}$, green, 18 to $8 \mathrm{cps}$, black and lower than $8 \mathrm{cps}$, cut-off.

\section{Case- I 57 years old male.}

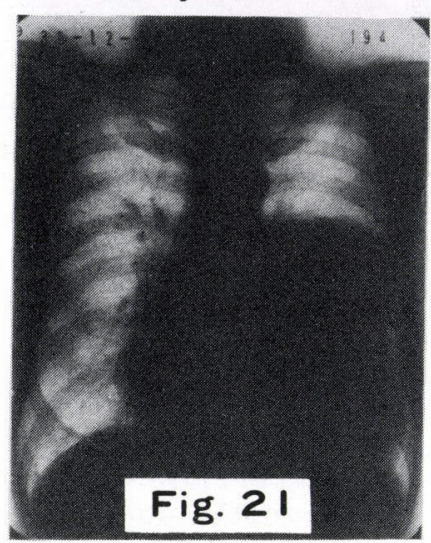

Case- 255 years old female.
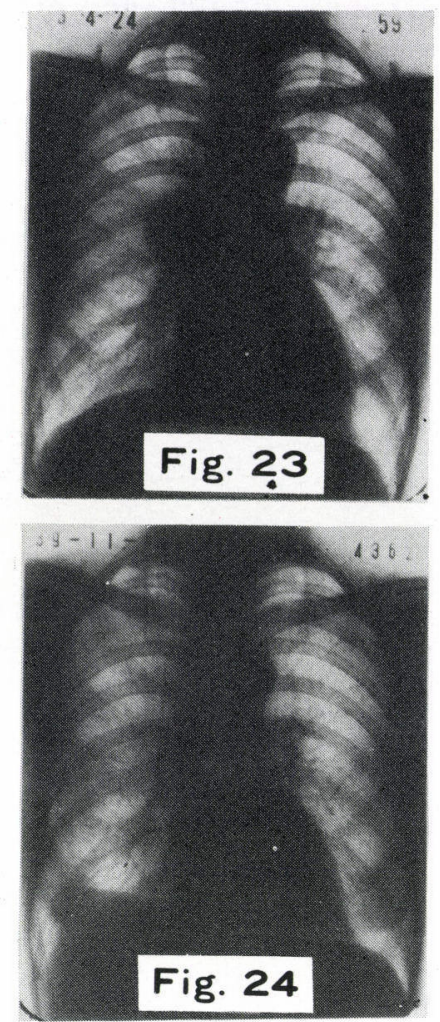

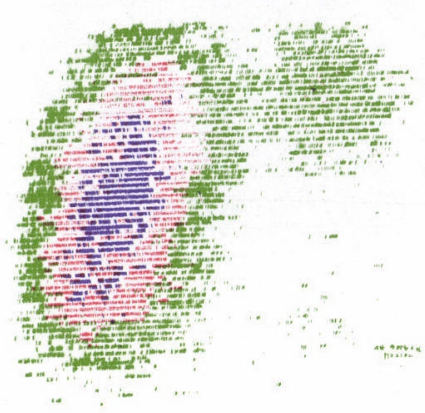

Fig. 22

Fig. 22. Color scintigram of pleuritis hypertrophicans.

Fig. 21. $\mathrm{X}$-ray finding of pleuritis hypertrophicans.

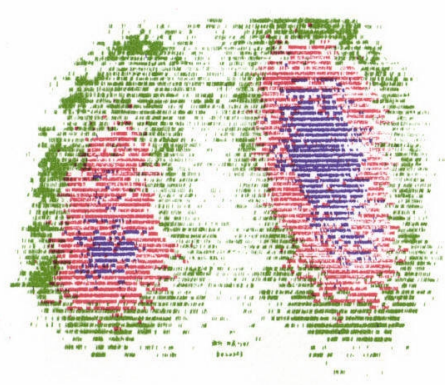

Fig. 25

Fig. 23. X-ray finding of lung cancer (Apr.1964)

Fig. 24. X-ray finding of healed lung cancer (Nov. 1964) after ${ }^{60} \mathrm{Co}$ teletherapy $(8000 \mathrm{r}$.). The tumor of hilar region has been disappeared.

Fig. 25. Color scintigram of lung cancer at same time with Fig. 24. 